\title{
Cryogenic Examination on Fiber Metal Laminates - A Short Critic
}

\author{
Jothiraj Palaniappan, Vignesh S, Winowlin Jappes J T
}

\begin{abstract}
Fiber Metal laminates (FML) have made its place in the prominence of the materials development whereby the study of its mechanical, physical, chemical characterization of the property of the material behavior have been studies and reported by various intellects. This paper delivers a scope of cryogenic treatment and the effect of the Fiber Metal laminates towards its property change and dialect behavior towards the subject of the material to the adverse cooling temperature. Every material holds a particular energy by its stances to the heat of addition which results due cause of the material heat absorption and quantum movement of the particles resulting in the energy due cause of molecular randomness.
\end{abstract}

Keywords: Fiber Metal Laminates, Cryogenic, Low temperature Aging

\section{INTRODUCTION}

The emphasis of cryogenic have started its way back in nineteenth century when few scientist tried to liquefy the permanent gases like oxygen, Nitrogen, etc. resulted in the phase change of the gaseous to liquid causing the material to lower the temperature adversely down to a critical temperature onto which the said permanent gaseous liquefies. The impact of cryogenic was phased outwards by the English Physicists Lord Kelvin when he stated the occurrences of the complete absence of the molecular motion due cause of complete absence of heat and temperature giving the scientist to forward the research towards making all the permanent gaseous to its complete cease known as Cryogenic critical state. The significance of the material towards its mechanical strength increases as being treated with the cryogenic liquids and thereby imparting the increase of hardness with the material causing the material to be more hardened by sacrificing the ductility of the materials. The cryogenic study have given way forth to the scientist to over enunciate the effect of superconductivity whereby the material get zero resistances to the flow of electron as the

Revised Manuscript Received on December 5, 2019

* Correspondence Author

Jothiraj Palaniappan*, Department of Mechanical Engineering, Kalasalingam Academy of Research and Education, Virudhunagar , India. Email: jothiraj@klu.ac.in

Vignesh S, Department of Mechanical Engineering, Kalasalingam Academy of Research and Education, Virudhunagar , India. Email: vignesh@klu.ac.in

Winowlin Jappes J T, Department of Mechanical Engineering, Kalasalingam Academy of Research and Education, Virudhunagar , India. Email: winowlin@klu.ac.in conduction of current in the circuit. Which have made the researcher to impart the varied studies on the cryogenic treatment in the metal and various alloys and studying the parametric changes of the materials.

\section{CRYOGENIC TREATMENT STUDIES ON FML}

Fiber metal laminates holds good to its varied properties as a constituent of materials in the laminates forms. The main advantages of the fiber metal laminates over the other metal and alloys holds its anisotropic characteristics properties which is due cause of the stacking of the various laminates over the other with different mechanical and chemical properties, though ensures the production of a material with the desired properties since it lies in the control of the manufacturer to control the desired parameters of the FML as a whole by controlling the parameters of the individual stacking of the various elements. The treatment of material below the temperature of $123 \mathrm{~K}$ relies on the range of the cryogenic temperature and in most cases the modulation of temperature to $173 \mathrm{~K}$ induces the cause of super elasticity in the material medium making the material to null resistance to the conduction and making the flow of electron with zero resistances.[1-2]. The cryogenic treatment studies on the laminates of fiber glass and epoxy laminates where studied under varied condition of $77 \mathrm{~K}$ and $296 \mathrm{~K}$ for both notched and un- notched plies of laminates and the result studied by $M$.Gong. et al [3] have significantly showed the behavior characteristic of a brittle material as in case of similar replication of the metal alloys making the clear prospect of the reduction of ductility of the material and the enhancement of the brittle characteristic induction by the material in subject of the conditioned with the cryogenic and the energy dissipation density increases with decrease of layup angles. The primary study have clearly illustrate the increase of the strength by $15-20 \%$ as compared to the treatment of the laminates from room temperature to cryogenic temperature. K. Logesh [15] have invariantly emphasized the various method of manufacturing of the fiber metal laminates and characterization techniques.

The emphasis of studies on the cryogenic treatment have evidenced even in the industrial scenario whereby the B C Ray [4] have elucidated the effect of linear and inter-laminar failure in the woven carbon fiber 50,55,60 percentage weight reinforced with the epoxy composite herein to study the characteristic failure behavior of the materials.

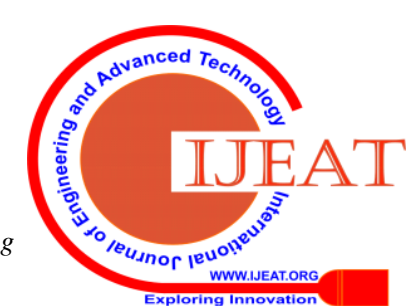




\section{Cryogenic Examination on Fiber Metal Laminates - A Short Critic}

The temperature damage mechanics was emphasized with the micro structural analysis, a high interfacial cracking and deboning were resulted with the cryogenic treatment, formation of row of cups due to the formation of coalesce was formed which signified the less interference in the usage of the cryogenic to positive impact raw epoxy composite leading to the inclusion of the metal laminates and its cryogenic studies.

Since then the addition of the metal laminates to the improved strength upon the treatment of the metals was characterized unto which S Kalia [5] invariantly studies the effect of addition of the matrix of fiber in GFRP composite and its mechanical characterization of the laminated under the cryogenic treatment and resulted in the improved behavior properties of fiber with volume fraction of 70:30 in ultimate tensile strength (UTS) and 75:25 gave higher flexural and impact strength. Since the development of the arena of materials towards the infliction of Nano technology have adversely made the researcher to motivate themselves to the adhere the properties of influence of the cryogenic as the behavior of the delamination and various process parameter shall vary accordingly with the inclusion of the substrate with the Nano material and have studied by various researchers Ram Kumar R [17] have made a précised elaboration of the review on various glass fiber epoxy composites incorporating CNT tubes associated with $\mathrm{Al} 2 \mathrm{O} 3$ along g with $\mathrm{Y}$. Shao et al[16] whereby the effect of cryogenic treatment on the Carbon nano tubes (CNT) with controlled cooling process have been studied and have evidenced the increase of bonding strength by $33 \%$ by thermal shrinkage of CNT tubes on the treatment of the cryogenic environments. $\mathrm{M}$. Najafi, [18] studied the effect of cryogenic aging in fiber metal laminates upon which the cryogenic aging was done at $-1960 \mathrm{C}$ for $336 \mathrm{~h}$ was calibrated and have conclude the negative impact of the GE ( Glass- Epoxy) composite towards its flexural stiffness and impact strengths

\section{CRYOGENIC ASSISTED MACHINABILITY STUDIES OF FML}

Machinability induced Cryogenic treatment in various material have made its path in the area of cryogenic whereby the effect of the improved machined characterization of the material and the tool life dependencies were studied by various researchers includes the article of $\mathrm{N}$ Govindaraju and Y Kanyak et al [6-7] to make the evaluation of the machining of Inconel 718 which is high temperature material and have showed improved machining parameter in terms of improved surface quality and reduced tool wear after the inclusion of the cryogenics. As discussed in the above article its clear that even the addition of the matrix and the laminated stacking also have shown the same effect of the reduced ductile strength and the improved hardness of the material along the laminates making the material to facilitate brittle zone effect to the material thus the case of the fatigue strength of the material determination was of the most concern whereby the researcher wanted to study about the inclusion of the repetitive load would cause to the material to which the researcher Van De Camp [8] elucidated the effect of fatigue and stress strain behavior of the Fiber metal laminates of
A12024/ stycast 2085 FT composite sandwiches under cryogenic treatment and found the increase of fatigue life have improved to around 20 times as compared to the normal room treated laminates. So as to encapsulate the result of the theoretical and practical stances of the fiber metal laminates study on the cryogenic model the base of the finite element modeling of the cryogenic model based machine analysis and in symbiosis was studies by A H Kheriddine and L S Ahmed et al. [9-10] whereby the researcher developed a model based cryogenic cooling and cutting parameters were used to predict the Zener Hollomon parameter value at the surface of the hole and have witnessed in the increase in the surface hardness as compared favorably with the FEM model constituting the Hall - Petch relations. Thereby this studies have evidenced in the usage of the model based studies associated with the fiber metal laminates and its coherences with the treatment of the cryogenics.

The significant of researchers have studied the impact of the usage of the cryogenic material and though the usage of the surface integrity by minimum quality lubrication (MQL) have analyzed by K. Giasin[11,13], since for any machining operation the usage of the lubricant have predominantly improved the machining output parameters thought the inclusion of both the desirable effect of the cryogenic treatment and the MQL have studies for GLARE fiber metal laminates and have significantly zest the usage have improvised the machinability and have reduced exit burr formation and have also emphasized the design of experiment to mend the machinability of the materials. As similar the cryogenic treatment of the CFRP composite materials was studied by T.Xia [12] and have resulted in the reduction on the cutting edge rounding of drill bit and outer corner wear and adverse to the result of the K Gasim[11], T. $\mathrm{Xia}$ [12] added the notion that cryogenic cooling in machining have generated larger thrust force, torque and thus larger delamination factors.

In any machining operation the condition of the process parameter and the optimization of its best part to find the better suitability lies its predominated role G. Basmaci et al,[15] investigated the impact of the cryogenic conditioning and drill diameter on Carbon fiber reinforced polymers using the methodology of dipped cryogenic machining the result have greatly influenced the drilled parameter and surface roughness and however it has increased the thrust force and delamination factor. On the combined study of Basmaci and Gasim it can be emphasized that the implication of the cryogenic treatment have greatly influenced the delamination factor of the laminates/composite as a whole.

The increased thermal effect because of the drilling assisted with its parameter causes the affect of quality of the FML and though influences the surface properties of the material though the cryogenic and various lubrication have made its role to the utmost potential K. Giasin [19] studied the hole perpendicularity error in fiber metal laminates and have shown the least or null influence of either cryogenic or MQL in the perpendicularity error of the fiber metal laminates. process. 


\section{CONCLUSION}

The prominent cause of the studies have entrusted various researcher and there studies of the cryogenic treatment of the fiber metal laminates. It was evidenced by many researcher as the metal because of its coherence in the range of isotropic characteristic nature have clearly shown the loss of ductility and the improvement of the metallic hardenability on the treatment over cryogenic which have been reflected as same in case of the fiber metal laminates owing to the loss of ductility and increase of the hardenability of the material even though the fiber metal laminates shown anisotropic characteristic in nature due to different stacking over varied constituents.

The increase of hardness have also been impacted its counterpart thereby increasing the laminated failure by influencing and enhancing the laminate delamination as studied by the researchers. The machining arena of the cryogenic have been a thrust area for many researcher since the inclusion of the cryogenic with the MQL have shown significance in the improvement of the machinability by eliminating the heat generation and reduced the tool wear. The increase in fatigue life of the tools have also been evidenced to the researcher which shall be accomplished to increase the process parameter optimization in the cryogenic constrain of the materials and its machining attributes. As suggested cryogenic too include its effect and affecting parameters so as to which the optimization and modeling analysis shall conglomerate the desirable influence and will eliminate the undesirable constrain in the machining of fiber metal laminates which is studies by researchers either by FEM models or the experimental analysis. Thus the fiber metal laminates can be desirously opted to the replacement of the material even in the phase of modern and adverse low temperature application in accordance to its process parameter optimization along with its counterparts of materials.

\section{REFERENCES}

1. V. T. Bechel, J. D. Camping, and R. Y. Kim, "Cryogenic/elevated temperature cycling induced leakage paths in PMCs," Compos. Part B Eng., vol. 36, no. 2, pp. 171-182, 2005.

2. B. C. Ray, "Effect of thermal shock On interlaminar strength of thermally aged glass fiber-reinforced epoxy composites," J. Appl. Polym. Sci., vol. 100, no. 3, pp. 2062-2066, 2006.

3. M. Gong, X. F. Wang, and J. H. Zhao, "Experimental study on mechanical behavior of laminates at low temperature," Cryogenics (Guildf)., vol. 47, no. 1, pp. 1-7, 2007.

4. M. Surendra Kumar, N. Sharma, and B. C. Ray, "Microstructural and mechanical aspects of carbon/epoxy composites at liquid nitrogen temperature," J. Reinf. Plast. Compos., vol. 28, no. 16, pp. 2013-2023, 2009.

5. S. Kalia and S. Y. Fu, "Polymers at cryogenic temperatures," Polym. Cryog. Temp., vol. 9783642353352, pp. 1-292, 2013.

6. [N. Govindaraju, L. Shakeel Ahmed, and M. Pradeep Kumar, "Experimental investigations on cryogenic cooling in the drilling of AISI 1045 steel," Mater. Manuf. Process., vol. 29, no. 11-12, pp. 1417-1421, 2014.

7. Y. Kaynak, "Evaluation of machining performance in cryogenic machining of Inconel 718 and comparison with dry and MQL machining," Int. J. Adv. Manuf. Technol., vol. 72, no. 5-8, pp. 919-933, 2014.
8. W. Van De Camp et al., "Cryogenic fatigue and stress-strain behavior of a fibre metal laminate," Phys. Procedia, vol. 67, pp. 1043-1048, 2015.

9. A. H. Kheireddine, A. H. Ammouri, T. Lu, O. W. Dillon, R. F. Hamade, and I. S. Jawahir, "An experimental and numerical study of the effect of cryogenic cooling on the surface integrity of drilled holes in AZ31B Mg alloy,” Int. J. Adv. Manuf. Technol., vol. 78, no. 1-4, pp. 269-279, 2015.

10. L. S. Ahmed and M. P. Kumar, "Cryogenic Drilling of Ti-6Al-4V Alloy Under Liquid Nitrogen Cooling," Mater. Manuf. Process., vol. 31, no. 7, pp. 951-959, 2016.

11. K. Giasin, S. Ayvar-Soberanis, and A. Hodzic, "The effects of minimum quantity lubrication and cryogenic liquid nitrogen cooling on drilled hole quality in GLARE fibre metal laminates," Mater. Des., vol. 89, pp. 996- 1006, 2016.

12. T. Xia, Y. Kaynak, C. Arvin, and I. S. Jawahir, "Cryogenic cooling-induced process performance and surface integrity in drilling CFRP composite material,” Int. J. Adv. Manuf. Technol., vol. 82, no. 1-4, pp. 605-616, 2016.

13. K. Giasin, S. Ayvar-Soberanis, and A. Hodzic, "Evaluation of cryogenic cooling and minimum quantity lubrication effects on machining GLARE laminates using design of experiments," J. Clean. Prod., vol. 135, pp. 533- 548, 2016.

14. G. Basmaci, A. Yoruk, U. Koklu, and S. Morkavuk, "Impact of Cryogenic Condition and Drill Diameter on Drilling Performance of CFRP," Appl. Sci., vol. 7, no. 7, p. 667, 2017.

15. K. Logesh, "Review on manufacturing of fibre metal laminates and its characterization techniques," Ijmet, vol. 8, no. 10, pp. 561-578, 2017.

16. Y. Shao et al., "Influence of cryogenic treatment on mechanical and interfacial properties of carbon nanotube fiber/bisphenol-F epoxy composite,” Compos. Part B Eng., vol. 125, pp. 195-202, 2017.

17. R. R. Kumar, E. A. ngo, K. P. vasan, and M. K. raja, "Cryogenic Treatment of Glass Fabric Epoxy Composites by Incorporating Cnt-A12o3 - A Review," Int. J. Mech. Eng., vol. 4, no. 12, pp. 22-25, 2018.

18. M. Najafi, R. Ansari, and A. Darvizeh, "Effect of cryogenic aging on nanophased fiber metal laminates and glass/epoxy composites," Polym. Compos., pp. 1-11, 2018.

19.K. Giasin, "The effect of drilling parameters, cooling technology, and fiber orientation on hole perpendicularity error in fiber metal laminates," Int. J. Adv. Manuf. Technol., vol. 97, no. 9-12, pp. 4081-4099, 2018.

\section{AUTHORS PROFILE}

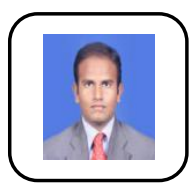

Jothiraj Palaniappan has completed his bachelor's degree in the department of Mechanical Engineering under Anna University with First rank and gold medal, proceeded with the degree of masters under the Manufacturing Engineering with First Rank and Gold medal. He is being nominated and selected as the Mentor for change under the NITI-Ayog, Govt. of India for AIM. Has published two papers in peer reviewed journals. Active member in the IAEng. Research interest being inclined towards the advanced materials as shape memory alloys and phase changing materials

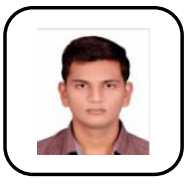

Vignesh $\mathbf{S}$ has graduated in the field of Mechanical Engineering from Anna University in 2013. He completed his post-graduation in Manufacturing Engineering from Anna University in 2016. His research area of interests are casting of non-ferrous alloys, development of polymer composites and mechanical behavior of materials. Presently he is working with Kalasalingam Academy of Research and Education as an Assistant professor in the department of Mechanical Engineering 
Winowlin Jappes J $\mathbf{T}$ graduated in 1997 from Manonmaniam Sunderanar University, India in Mechanical Engineering. In 1999, he has completed his masters in Production Engineering from Annamalai University. He completed his Ph.D degree in 2004 in the area of Composite Deposition at Indian Institute of Technology Madras, Chennai. He has completed three DST funded research projects and published more than 125 research articles which includes 65 International Journal papers. Currently, he is working as Senior Professor in Kalasalingam University, India. His research interests includes high performance composite materials, machining of hard materials, optimization techniques, etc. At present, he is working as Professor and Dean, School of Automotive and Mechanical Engineering, Kalasalingam Academy of Research and Education, India. 